\title{
A narrative review of combining radiation and immunotherapy in gastroesophageal cancers
}

\author{
Kevin Yoon ${ }^{1}$, Yi-Jen Chen ${ }^{2}$, Joseph Chao ${ }^{3}$ \\ ${ }^{1}$ Department of Internal Medicine, Harbor UCLA Medical Center, Torrance, CA, USA; ${ }^{2}$ Department of Radiation Oncology, City of Hope \\ Comprehensive Cancer Center, Duarte, CA, USA; ${ }^{3}$ Department of Medical Oncology \& Therapeutics Research, City of Hope Comprehensive \\ Cancer Center, Duarte, CA, USA \\ Contributions: (I) Conception and design: All authors; (II) Administrative support: None; (III) Provision of study materials or patients: None; (IV) \\ Collection and assembly of data: None; (V) Data analysis and interpretation: None; (VI) Manuscript writing: All authors; (VII) Final approval of \\ manuscript: All authors. \\ Correspondence to: Joseph Chao, MD. City of Hope Comprehensive Cancer Center, 1500 East Duarte Road, Duarte, CA 91010, USA. \\ Email: jchao@coh.org.
}

\begin{abstract}
Despite advances in chemotherapy, radiation, and surgery, prognosis in gastroesophageal cancers (GEC) remains poor. Recent studies have demonstrated that immune checkpoint inhibitors specific to the PD-1/PD-L1 axis can improve survival with dramatic durability for a subset of patients with GEC. Radiation therapy (RT) has been shown to enhance priming and anti-tumor immunogenicity. The combination of these two treatments has shown promising results acting synergistically in pre-clinical and clinical models. Much of this synergy appears linked to in-field radiation responses, but also the abscopal response where out-of-field tumors demonstrate regression. In this review, we summarize the current role of immunotherapy and radiation in GEC. We also highlight progress from preclinical studies and translational biomarker analyses that provide rationale for ongoing efforts combining immune checkpoint inhibition and radiotherapy specifically in GECs. Questions that remain unanswered in the clinic are the optimal radiation dosing, timing, and fractionation strategies to augment abscopal immune responses. Increasing recognition of the heterogeneity of immunosuppressive mechanisms that can arise in response to radiation indicates the need for novel immune checkpoint inhibitors that target beyond the PD-1/PD-L1 axis. Smartly designed prospective trials incorporating these two approaches with ongoing translational analyses will be critical in increasing the success of combinatorial radiation and immunotherapy strategies in this disease.
\end{abstract}

Keywords: Abscopal effect; gastroesophageal cancer (GEC); immunotherapy; immune checkpoints; radiation therapy (RT)

Submitted May 29, 2020. Accepted for publication Jul 24, 2020.

doi: $10.21037 /$ tcr-20-2210

View this article at: http://dx.doi.org/10.21037/tcr-20-2210

\section{Introduction}

Gastric and esophageal cancer remains a major cause of cancer-associated deaths. In 2019, it was estimated that there were approximately 11,000 deaths due to gastric cancer and 16,000 deaths due to esophageal cancer in the U.S (1). To improve clinical outcomes for patients with locally advanced non-metastatic disease, a combination of radiation, chemotherapy, and surgery has been the fundamental approach.
Despite the multidisciplinary approach to therapy, the prognosis of gastroesophageal cancer (GEC) patients remains poor due to recurrence, development of metastasis and treatment complications (2). Advances in nextgeneration sequencing have led to the discovery of several processes that contribute to carcinogenesis, driver gene mutations, dysregulation of cellular signaling pathways and alterations of the tumor microenvironment. The successful use of immune checkpoint inhibitors including 
programmed death 1/programmed death ligand 1 (PD-1/ PD-L1) inhibitors have improved the prognosis of various malignancies including melanoma and non-small cell lung cancer $(3,4)$. However, the majority of patients with metastatic GECs do not garner a response to single agent immune checkpoint inhibitors (5).

Traditionally, radiation therapy (RT) has been widely used for local tumor control. However, growing evidence has shown RT's ability to generate a systemic immune response to decrease the burden of metastases outside of the radiation field aptly named the abscopal effect (6). Growing evidence supports that the abscopal effect is likely driven by $T$ cell-dependent processes involving immunogenic and proinflammatory pathways (7-15). Previously, the reports of abscopal effects have been limited to 46 cases over 45 years (16). The possible explanation for the rarity of the abscopal effects despite the pro-immunogenic mechanisms of RT is that cancers establish a strong immunosuppressive tumor microenvironment (17). Numerous phase II/III clinical trials in tumor histologies outside of GEC have explored combining checkpoint inhibition with RT to improve anti-tumor effects $(18,19)$. In this review article, we discuss the current role of immunotherapy and radiation in GECs. Also, we highlight the rationale behind preclinical studies and clinical studies that are exploring a potential role for the combination of checkpoint inhibition and RT specifically in GECs. We present the following article in accordance with the narrative review reporting checklist (available at http://dx.doi.org/10.21037/tcr-20-2210).

\section{The rationale for immune checkpoint blockade in GEC}

$\mathrm{T}$ cells are activated by the adaptive immune response during carcinogenesis. However, cancer cells can escape immune response by controlling immune checkpoint pathways typically reserved for restraining of pathologic autoimmunity (20). Over the past several years, immune checkpoint inhibitors have emerged as a powerful tool in the treatment of cancer. Typically engineered as monoclonal antibodies, these agents can inhibit immune checkpoints, putatively restoring $\mathrm{T}$ cell response against dysregulated cancer cell growth. Currently approved antibodies include cytotoxic T-lymphocyte-associated protein 4 (CTLA-4) inhibitors, PD-1 and PD-L1 inhibitors.

The PD-1/PD-L1 axis has emerged as a major immune checkpoint whose targeting has yielded favorable outcomes in a subset of patients with GEC. Unlike other solid tumors (such as melanoma, lung or renal cell carcinoma), for GEC PD-L1 expression in tumor cells is relatively low and is mostly observed in infiltrating myeloid cells at the invasive margins (21-23). In addition, prevalence of PD-L1 overexpression may be influenced by the major molecular subclassifications characterized by The Cancer Genome Atlas (TCGA) for GEC, i.e., tumors associated with Epstein Barr virus (EBV), microsatellite instability (MSI), genome stability (GS) and chromosomal instability (CIN) (24). For instance, EBV associated gastric cancers express PD-L1 in tumor cells and immune cells in approximately $50 \%$ and $94 \%$ of cases, respectively (25). The presence of MSI is also associated with PD-L1 expression on tumor cells and immune cells (33\% and $45 \%$ of cases, respectively) (25). As of 2017, detection of DNA mismatch repair deficiency (MMR-D) and MSI garnered regulatory approval as biomarkers predicting for benefit from PD-1 inhibitors in GEC (26).

Initial U.S. regulatory approval for pembrolizumab for metastatic gastric and GEJ adenocarcinomas stemmed from the multi-cohort phase II KEYNOTE-059 trial (27). The largest cohort (Cohort 1), was composed of patients refractory to at least 2 lines of systemic therapy. In patients with GEC PD-L1 expression as defined by the Combined Positive Score (CPS) of at least 1, i.e., at least 1 tumor cell and/or immune cell out of 100 viable tumor cells demonstrating PD-L1 immunohistochemical (IHC) staining, objective response rate (ORR) was $15.5 \%$. Despite the modest proportion of patients garnering a response, accelerated approval was granted due to the durability of the responses observed manifested by the median duration of response being 16.3 months. Among 7 patients confirmed to have MSI-High (MSI-H) tumors, ORR was much higher $(57.1 \%)$ versus an ORR 9.0\% among 167 patients with non-MSI-H tumors, reinforcing TCGA molecular subclassifications correlating with immune checkpoint upregulation and propensity to respond to immune checkpoint inhibitors. The phase III ATTRACTION-2 study of best supportive care with addition of nivolumab versus placebo provided further evidence that at least in the third-line setting, PD-1 inhibitors provide clinical meaningful benefit to a subset of patients with GEC (28). This was manifested by an ORR of $11.2 \%$ and of note the authors did not ascertain PD-L1 CPS as a predictive biomarker, but ascertained only tumor cell PD-L1 expression. With this methodology GEC patients either with the presence or absence of PD-L1 expression still yielded survival benefit when assigned to nivolumab versus 
placebo. Given the study did still meet its prespecified endpoint of improving survival in a GEC patient population enrolled at multiple Asian centers, nivolumab garnered regulatory approval for third-line therapy in Japan independent of tumor biomarker status.

Subsequent randomized trials examining introduction of PD-1 inhibitors in earlier lines of therapy, such as the KEYNOTE-061 study, demonstrated the limitations with observing durable responses in only a minority of GEC patients in contrast to broader, albeit transient responses garnered from chemotherapy (29). The authors randomized 592 patients refractory to first line therapy to either receive pembrolizumab $200 \mathrm{mg}$ every 3 weeks for up to 2 years or standard doses of paclitaxel. The pembrolizumab arm had modestly improved median OS (9.1 vs. 8.3 months) but inferior median progression-free survival (PFS) (1.5 vs. 4.1 months). In subgroup analyses, the authors reported improved response rates in patients with increased PD-L1 CPS $\geq 10$ (24.5\% vs. $9.1 \%)$ and in MSI-H tumors irrespective of PD-L1 CPS score (46.7\% vs. $16.7 \%$ ). A similar pattern has also emerged from clinical trial data in esophageal squamous cell carcinomas (ESCC). From the randomized phase III ATTRACTION-3 trial, all patients enrolled were diagnosed with unresectable advanced ESCC and randomized to second line nivolumab or standard of care chemotherapy, and ORR was $19 \%$ versus $22 \%$, respectively (30). Majority of patients (55\%) receiving nivolumab demonstrated progressive disease as best response versus $32 \%$ in the patients assigned to chemotherapy. From the phase III KEYNOTE-181 trial that enrolled patients with both adenocarcinoma and ESCC histology, tumor PD-L1 CPS $\geq 10$ status appeared to enrich for likelihood of benefit from pembrolizumab as ORR was $21.5 \%$ in this subset versus only $6.1 \%$ when these patients were assigned to chemotherapy (31). However, tumors with a PD-L1 CPS $\geq 10$ appear to only carry a prevalence of $~ 30 \%$ in patients with GEC. In summary, single agent immune checkpoint inhibitors have yielded meaningful clinical benefit in the treatment of metastatic GEC, albeit confined to a small proportion of all-comers with GEC regardless of adenocarcinoma or squamous cell carcinoma histology.

\section{Current role of RT in non-metastatic GEC}

In localized GECs, surgical resection remains central as a treatment modality and is potentially curative. However, surgical management alone is associated with high recurrence rates. A multidisciplinary approach of incorporating chemotherapy, radiation, and surgery have shown improvement in outcomes over the years in GECs (32-34). Traditionally, it has been thought that ionizing radiation on local tumor cells leads to direct or indirect DNA damage which triggers a series of molecular events associated with cell death (35). Prior studies demonstrating the therapeutic benefit of a single agent or combination chemotherapy in patients with esophageal cancer led to question if the combination of chemotherapy plus radiation is superior to RT alone in non-metastatic GECs (36-40). In one of the early seminal trials, Herskovic et al. randomly assigned patients $(\mathrm{n}=121)$ with locally advanced but non-metastatic squamous-cell carcinoma or adenocarcinoma of the esophagus to combined fluorouracil and cisplatin plus 5,000 cGy of radiation or 6,400 cGy of RT alone (41). The authors found improved median survival (12.5 vs. 8.9 months) in favor of the chemoradiation arm. Higher rates of survival were also noted in the chemoradiation arm than radiation alone arm at 12 months (33\% vs. $10 \%)$ and 24 months (50\% vs. $38 \%, \mathrm{P}<0.001)$. Although there were limitations to how the recurrences were detected, the authors observed fewer local and distant recurrences in the chemoradiation arm compared to the radiation alone arm. The evidence for the efficacy of chemoradiation was further strengthened when a French study demonstrated non-inferiority of definitive chemoradiation versus chemoradiation followed by surgery in locally advanced esophageal predominantly squamous cell carcinomas (42).

Given the high relapse rate after the resection of cancer, adjuvant and neoadjuvant approaches have been investigated to improve outcomes. The Southwestern Oncology Group/Intergroup (SWOG/INT) 0116 trial demonstrated efficacy of adding adjuvant chemoradiation in surgically resected gastric and gastroesophageal junction (GEJ) adenocarcinomas (43). The RT portion of adjuvant chemoradiation consisted of 45 Gy given as 1.8 Gy daily for 5 days per week for 5 weeks. The authors observed an improved median overall survival (OS) of 36 months in the chemoradiation arm compared to 27 months in the surgery only arm (HR 1.35; 95\% CI: 1.09-1.66; P=0.005). Neoadjuvant chemoradiation is also an established approach in non-metastatic esophageal and GEJ cancers as highlighted in multiple trials including the Cancer and Leukemia Group B (CALGB) 9781 trial and the CROSS study (Chemo Radiotherapy for Oesophageal cancer followed by Surgery Study). The CALGB 9781 
trial demonstrated the efficacy of cisplatin and 5-FU based concurrent chemoradiation followed by surgery was superior to surgery alone (44). The rate of complete pathologic response was also found to be $40 \%$ with employment of neoadjuvant chemoradiation. However, the trial was limited by a lack of a large sample size (56 patients instead of 500 patients which the authors initially intended to accrue). The CROSS study was a much larger phase III trial that validated the efficacy of neoadjuvant chemoradiation. The authors randomized 366 patients with locally advanced esophageal or GEJ cancers (clinical stage T1N1M0 or T2$3 \mathrm{~N} 0-1 \mathrm{M} 0$, according to the $6^{\text {th }}$ edition of the TNM staging system) (45). The authors compared chemoradiation (41.4 Gy concurrent with weekly carboplatin/paclitaxel) followed by surgery to surgical resection alone. The neoadjuvant chemoradiation arm improved local control of the disease exemplified by a significant improvement in negative margin resection rates $(92 \%$ vs. $67 \% \mathrm{P}<0.001)$. Notably, in patients with squamous cell histology, the pathologic complete response rate was $49 \%$ (18 of 37 patients) compared with $23 \%$ (28 of 121 patients) in patients with adenocarcinoma histology. Traditionally, lack of complete pathologic responses to chemoradiation has been ascribed to tumor cell intrinsic mechanisms, though in the following sections we review data where modulation of the tumor immune microenvironment may play a role in GECs. Such datasets pave the way for combining immune checkpoint blockade and RT improving outcomes in this disease.

\section{The rationale for combining radiation and immune checkpoint blockade in GEC}

Growing evidence from preclinical models and clinical datasets has shown that RT can exert systemic anti-tumor effects through the innate and adaptive immune system. RT can provide immunogenic activity through a variety of mechanisms. These include activating immunogenic cell death (46), producing neoantigens, antigen processing and cross-presentation (47), decreasing the immunosuppressive tumor microenvironment $(48,49)$, overcoming T-cell exclusion from the tumor microenvironment (50) and increasing tumor recognition by the immune system (47). The idea of RT induced systemic immune responses to cancers was described by Mole in 1953, deemed the abscopal effect (6). In essence, tumor irradiation at the primary site can cause immune-mediated tumor reduction at the distant sites.
However, in terms of the abscopal effect of RT not being more robust, preclinical studies have partly attributed this to upregulation of the PD-1 pathway. This was exhibited in a mouse model of primary melanoma where the authors compared abscopal reduction in tumor burden in secondary non-irradiated tumors in PD-1 knockout mice compared to PD-1 wildtype (WT) mice where the targeted tumor was treated with 15 Gy of stereotactic ablative radiotherapy (SABR) (51). The tumor volume reduction in non-irradiated secondary sites was much greater in PD-1-knockout mice compared to WT mice. The addition of a PD-1 inhibitor to SABR also enhanced anti-tumor activity and abscopal effects on distal non-irradiated tumors in PD-1-WT mice when compared with mice that were treated with SABR alone. Furthermore, higher concentrations of PD-1+, CD11a, and CD8+ T-cells were seen in irradiated tumors compared to non-irradiated secondary tumors. The authors noted that immune cells that arose from irradiated tumor cells appeared to be generated against antigens from the specific tumor phenotype. This finding was reaffirmed in another study in which RT increased T-cell receptor clonality and diversity in irradiated tumors compared to controls (51). Interestingly, the combination of PD-1 inhibition and RT increased TCR diversity in both irradiated and secondary tumor sites (51).

However, the optimal radiotherapy dosing and fractionation scheme needed to generate the desired immunogenicity remains to be fully elucidated. Some preclinical investigations showed that immunogenic anti-tumor activity was dose dependent (18). Other studies have shown that increasing radiation doses (fractions above 7.5 Gy but not $5 \mathrm{~Gy}$ ) was associated with immunogenic anti-tumor activity with elevations in IFN-gamma but not Tregs. Doses of greater or equal to 15 Gy were not associated with improved anti-tumor activity (52). In another pre-clinical study, a single dose and two multiple-dose fractionation regimens $(20 \mathrm{~Gy} \times 1,8 \mathrm{~Gy} \times 3$, or $6 \mathrm{~Gy} \times 5)$ combined with CTLA-4 inhibitors were compared (53). The authors found that although all approaches decreased primary tumor burden, the fractionated regimens were able to achieve greater abscopal effect in the non-irradiated secondary sites. They also found that a multiple fraction approach of 8 Gy $\times 3$, combined with CTLA-4 inhibition generated a greater abscopal effect than a single fraction approach of 20 Gy $\times 1$. Currently, there has yet to be reported a clinical trial randomizing patients to differing radiation dosefractionation regimens in evaluating their ability to generate an abscopal effect (54). 
Focusing on GEC, PD-L1 among other immune checkpoint biomarkers have been observed to be upregulated after chemoradiotherapy in GECs, pointing to creation of an immunosuppressive tumor microenvironment induced by this modality. In a case series of 31 patients with resected esophageal adenocarcinoma after neoadjuvant chemoradiotherapy, increased IHC positivity of immune checkpoints including PD-L1 were observed in the postneoadjuvant therapy versus baseline tumor samples (PDL1, 45.16\% vs. $77.42 \%, \mathrm{P}=0.01$, OR=6.5; CTLA-4, $61.29 \%$ vs. $80.65 \%, \mathrm{P}=0.752, \mathrm{OR}=1.5)(55) . \mathrm{CD} 8+\mathrm{T}$ cells were also found to be increased after neoadjuvant therapy with a mean increase of $5.5 \mathrm{CD} 8+\mathrm{T}$ cells per 100 tumor cells $(\mathrm{P}=0.02)$, indicative of a pro-inflammatory state. A higher concentration of TILs was also found in the invasive front of the tumor stroma. Furthermore, higher gene expression of IFN-gamma and other markers for immune checkpoints (TIM3, GITR, IDO1, LAG3, OX40, and KIR) were found in post-treatment tumors with the exception of CD137. The authors inferred that there is significant heterogeneity of immunosuppressive mechanisms, and future studies should address the combination of different checkpoint inhibitors along with PD-1/PD-L1. After stratification by postneoadjuvant PD-L1 status, there were significant differences in relative quantification values (measure of changes in mRNA levels at steady state, RQ) for PD-L1+ compared to PD-L1- patients for immune checkpoints including GITR, TIM3, and OX40. Although mean RQ values were not significantly different for other checkpoints, the PDL1+ group had higher mean RQ values than the PD-L1group for all immune checkpoint genes. The authors also pursued mechanistic studies in a rat model of esophageal adenocarcinoma where they were able to vary the dose of RT delivered to tumors. They did observe that a higher dose of 16 vs. 13 Gy induced a higher fold-change in PDL1 expression when tumors were analyzed at 1 week $(3.30$ vs. 1.23), 3 weeks (1.65 vs. 1.23), and 5 weeks (3.92 vs. 1.44) after RT, though these differences did not meet statistical significance. The temporal increase in tumor PD-L1 expression also appeared to be dynamic, as resampling of esophageal tumors in this rat model at 9 weeks after RT exposure demonstrated return of PD-L1 expression to baseline levels.

An additional case series of 28 patients with gastric cardia and GE junction cancers treated with neoadjuvant chemoradiation followed by surgery were analyzed for tumor PD-1 and PD-L1 expression in pre-treatment and posttreatment samples (56). Similar to the study by Kelly et al., the authors also observed following chemoradiotherapy an increase in PD-1 and PD-L1 expression levels among $32 \%$ and $54 \%$ of this patient cohort, respectively. They also observed poorer survival in patients with higher post-treatment tumor PD-1 expression versus those with lower post-treatment $\mathrm{PD}-1$ expression (median survival 23.1 versus 74.1 months, $\mathrm{P}=0.039$ ). This data adds to growing observations that GECs mediate resistance to chemoradiation through upregulation of immune checkpoints in the tumor microenvironment. A preclinical mouse model of ESCC also demonstrated the greatest synergy against tumor growth when anti-PD-1 therapy was combined with chemoradiation versus just anti-PD-1 therapy alone, chemotherapy alone, or anti-PD-1 therapy plus chemotherapy (57). Interestingly, in this mouse model contralaterally injected tumors not directly targeted by the RT demonstrated increased CD8+ TILs and a decreased $\mathrm{T}$ cell exhausted phenotype when anti-PD-1 therapy was included, suggesting an abscopal response.

\section{Ongoing trials investigating synergy of RT with immunotherapy for GE cancers}

Based on promising potential from preclinical trials, numerous of clinical trials are underway to study the effect of RT combined with immune checkpoint inhibition in patients with GEC. Encouraging preliminary results from a phase I trial of neoadjuvant nivolumab plus chemoradiation in stage II/III esophageal/GEJ cancer has been published in abstract form (58). Therapy appeared tolerable with 14/16 patients able to receive all 5 intended doses of neoadjuvant nivolumab (14-day cycles, 2 doses prior to chemoradiation and 3 doses concurrent with chemoradiation). A complete pathologic response rate of $31 \%(5 / 16)$ was observed, with $15 / 16$ patients who underwent surgery not demonstrating disease recurrence at initial reporting. Building upon the reports of PD-1/PD-L1 immune checkpoints being upregulated after chemoradiation in GEC, the randomized phase III Checkmate-577 trial is examining whether adding adjuvant nivolumab versus placebo for patients without pathologic complete responses after neoadjuvant chemoradiation and surgery will improve long term overall and disease-free survival outcomes. This trial has completed accrual, and study results are eagerly awaited at the time of this review's publication, given positive results will change the paradigm for the use of PD-1 inhibitors in nonmetastatic GEC. Additional trials are underway to elucidate the efficacy of combining immunotherapy approaches and 
Table 1 Ongoing clinical trials evaluating combinational immunotherapy and RT approaches in GEC

\begin{tabular}{|c|c|c|c|c|c|c|}
\hline $\begin{array}{l}\text { Clinical trial } \\
\text { number }\end{array}$ & Target & Agents & Phase & Treatment & Condition & Primary end points \\
\hline NCT 02642809 & PD-1 & Pembrolizumab & 1 & $\begin{array}{l}\text { Pembrolizumab + } \\
\text { brachytherapy }\end{array}$ & $\begin{array}{l}\text { Metastatic esophageal } \\
\text { cancer }\end{array}$ & $\begin{array}{l}\text { Tolerability, treatment } \\
\text { related adverse events }\end{array}$ \\
\hline NCT 02844075 & PD-1 & Pembrolizumab & 2 & $\begin{array}{l}\text { Neoadjuvant pembrolizumab } \\
+ \text { paclitaxel + carboplatin + } \\
\text { RT + surgery }\end{array}$ & $\begin{array}{l}\text { Esophageal squamous cell } \\
\text { carcinoma }\end{array}$ & $\begin{array}{l}\text { Complete pathologic } \\
\text { response rate }\end{array}$ \\
\hline NCT 02830594 & PD-1 & Pembrolizumab & 2 & $\mathrm{RT}$ + pembrolizumab & $\begin{array}{l}\text { Esophageal squamous cell } \\
\text { carcinoma, esophageal } \\
\text { adenocarcinoma, } \\
\text { gastroesophageal } \\
\text { junction, and gastric } \\
\text { adenocarcinoma }\end{array}$ & $\begin{array}{l}\text { Biomarkers and } \\
\text { outcome }\end{array}$ \\
\hline NCT02743494 & PD-1 & Nivolumab & 3 & $\begin{array}{l}\text { Nivolumab vs. placebo. prior } \\
\text { to randomization, patients to } \\
\text { have completed preoperative } \\
\text { CRT + surgery }\end{array}$ & $\begin{array}{l}\text { Esophageal/ } \\
\text { gastroesophageal junction } \\
\text { cancer }\end{array}$ & Disease-free survival \\
\hline NCT 03278626 & PD-1 & Nivolumab & $1 / 2$ & $\begin{array}{l}\text { Nivolumab + paclitaxel + } \\
\text { carboplatin + RT }\end{array}$ & $\begin{array}{l}\text { Locally advanced } \\
\text { esophageal squamous cell } \\
\text { carcinoma }\end{array}$ & $\begin{array}{l}\text { Unacceptable } \\
\text { toxicity grade } 3,4 \text {, } \\
\text { hematologic toxicity }\end{array}$ \\
\hline NCT 03544736 & PD-1 & Nivolumab & $1 / 2$ & $\begin{array}{l}\text { Nivolumab + RT; nivolumab } \\
\text { + paclitaxel, carboplatin + } \\
\text { RT; nivolumab + paclitaxel, } \\
\text { carboplatin + surgery }\end{array}$ & Esophageal cancer & $\begin{array}{l}\text { Incidence of treatment- } \\
\text { emergent adverse } \\
\text { events, safety and } \\
\text { tolerability }\end{array}$ \\
\hline NCT 03044613 & $\begin{array}{l}\text { PD-1/ } \\
\text { LAG-3 }\end{array}$ & $\begin{array}{l}\text { Nivolumab + } \\
\text { relatlimab }\end{array}$ & 1 & $\begin{array}{l}\text { Nivolumab + carboplatin, } \\
\text { paclitaxel + RT; nivolumab } \\
\text { + relatlimab + carboplatin + } \\
\text { paclitaxel + RT }\end{array}$ & $\begin{array}{l}\text { Stage II/III gastric cancer, } \\
\text { esophageal cancer, } \\
\text { gastroesophageal cancer }\end{array}$ & $\begin{array}{l}\text { Treatment-related } \\
\text { adverse events }\end{array}$ \\
\hline NCT 03278626 & PD-1 & Nivolumab & 1 & $\begin{array}{l}\text { Nivolumab + carboplatin, } \\
\text { paclitaxel + RT }\end{array}$ & $\begin{array}{l}\text { Esophageal squamous cell } \\
\text { carcinoma }\end{array}$ & $\begin{array}{l}\text { Unacceptable toxicity } \\
\text { grade } 3,4\end{array}$ \\
\hline NCT 03490292 & PD-L1 & Avelumab & $1 / 2$ & $\begin{array}{l}\text { Avelumab + carboplatin, } \\
\text { paclitaxel + RT }\end{array}$ & $\begin{array}{l}\text { Reselectable esophageal } \\
\text { carcinoma }\end{array}$ & $\begin{array}{l}\text { Dose limiting } \\
\text { measures, pathologic } \\
\text { response rate, } \\
\text { pathological complete } \\
\text { response rate }\end{array}$ \\
\hline NCT 02520453 & PD-L1 & Durvalumab & 2 & $\begin{array}{l}\text { Neoadjuvant concurrent CRT } \\
\text { + surgery + duvalumab }\end{array}$ & $\begin{array}{l}\text { Esophageal squamous cell } \\
\text { carcinoma }\end{array}$ & Disease free survival \\
\hline
\end{tabular}

Table 1 (continued) 
Table 1 (continued)

\begin{tabular}{|c|c|c|c|c|c|c|}
\hline $\begin{array}{l}\text { Clinical trial } \\
\text { number }\end{array}$ & Target & Agents & Phase & Treatment & Condition & Primary end points \\
\hline NCT 03377400 & PD-L1 & $\begin{array}{l}\text { Durvalumab/ } \\
\text { tremelimumab }\end{array}$ & 2 & $\begin{array}{l}\text { Fluorouracil, cisplatin + RT + } \\
\text { durvalumab/tremelimumab }\end{array}$ & $\begin{array}{l}\text { Esophageal squamous cell } \\
\text { carcinoma }\end{array}$ & Disease free survival \\
\hline NCT 03087864 & PD-L1 & Atezolizumab & 2 & $\begin{array}{l}\text { Atezolizumab + carboplatin, } \\
\text { paclitaxel + RT }\end{array}$ & Esophageal carcinoma & Feasibility \\
\hline NCT03165994 & CD40 & APX005M & 2 & $\begin{array}{l}\text { APX005M + paclitaxel + } \\
\text { carboplatin + RT + surgery }\end{array}$ & $\begin{array}{l}\text { Esophageal cancer, } \\
\text { gastroesophageal cancer }\end{array}$ & $\begin{array}{l}\text { Safety, feasibility } \\
\text { pathologic complete } \\
\text { response rate }\end{array}$ \\
\hline
\end{tabular}

RT, radiation therapy; GEC, gastroesophageal cancer; PD-1, programmed death 1; PD-L1, programmed death ligand 1; CTLA-4, cytotoxic

T-lymphocyte-associated protein 4.

differing doses, delivery techniques, and duration of RT (Table 1).

\section{Conclusions}

Growing pre-clinical and clinical evidence continues to support radiation and immunotherapy as an important part of available treatment modalities for GECs. The combination of these two modalities has shown significant potential in various types of locally advanced or metastatic malignancies including GECs. RT remains promising for its potential in generating the abscopal effect. However, there remains no clear consensus in optimal dosing, timing and fractionation strategy to induce the abscopal effect. Also, the underlying mechanisms of anti-tumor activity generated by RT are complex and heterogenous. Combining RT with immune checkpoint inhibition will likely be necessary with the emerging data in GEC of an immunosuppressive tumor microenvironment resulting from RT. Optimizing RT fraction number, dosing, timing, duration and coadministration of appropriate immune checkpoint inhibitors while minimizing adverse events will be a challenge. The insights highlighted in this review suggest that the combination of radiation and immunotherapy will be a viable treatment option for GECs.

\section{Acknowledgments}

Funding: None.

\section{Footnote}

Provenance and Peer Review: This article was commissioned by the Guest Editors (Dr. Arya Amini and Dr. Tyler Robin) for the series "Synergy in Action: Novel Approaches to Combining Radiation Therapy and Immunotherapy" published in Translational Cancer Research. The article has undergone external peer review.

Reporting Checklist: The authors have completed the narrative review reporting checklist. Available at http:// dx.doi.org/10.21037/tcr-20-2210

Conflicts of Interest: All authors have completed the ICMJE uniform disclosure form (available at http://dx.doi. org/10.21037/tcr-20-2210). The series "Synergy in Action: Novel Approaches to Combining Radiation Therapy and Immunotherapy" was commissioned by the editorial office without any funding or sponsorship. JC reports grants and personal fees from Merck, personal fees from Amgen, personal fees from Macrogenics, personal fees from Ono Pharmaceuticals, personal fees from Foundation Medicine, outside the submitted work. The authors have no other conflicts of interest to declare.

Ethical Statement: The authors are accountable for all aspects of the work in ensuring that questions related to the accuracy or integrity of any part of the work are appropriately investigated and resolved. 
Open Access Statement: This is an Open Access article distributed in accordance with the Creative Commons Attribution-NonCommercial-NoDerivs 4.0 International License (CC BY-NC-ND 4.0), which permits the noncommercial replication and distribution of the article with the strict proviso that no changes or edits are made and the original work is properly cited (including links to both the formal publication through the relevant DOI and the license). See: https://creativecommons.org/licenses/by-nc-nd/4.0/.

\section{References}

1. Siegel RL, Miller KD, Jemal A. Cancer statistics, 2019. CA Cancer J Clin 2019;69:7-34.

2. Ferlay J, Soerjomataram I, Dikshit R, et al. Cancer incidence and mortality worldwide: Sources, methods and major patterns in GLOBOCAN 2012. Int J Cancer 2015;136:E359-86.

3. Karlsson AK, Saleh SN. Checkpoint inhibitors for malignant melanoma: a systematic review and metaanalysis. Clin Cosmet Investig Dermatol 2017;10:325-39.

4. Herzberg B, Campo MJ, Gainor JF. Immune Checkpoint Inhibitors in Non-Small Cell Lung Cancer. Oncologist 2017;22:81-8.

5. Lin EM, Gong J, Klempner SJ, et al. Advances in immunooncology biomarkers for gastroesophageal cancer: Programmed death ligand 1, microsatellite instability, and beyond. World J Gastroenterol 2018;24:2686-97.

6. Mole RH. Whole Body Irradiation-Radiobiology or Medicine? Br J Radiol 1953;26:234-41.

7. Demaria $\mathrm{S}, \mathrm{Ng}$ B, Devitt ML, et al. Ionizing radiation inhibition of distant untreated tumors (abscopal effect) is immune mediated. Int J Radiat Oncol Biol Phys 2004;58:862-70.

8. Ma Y, Kepp O, Ghiringhelli F, et al. Chemotherapy and radiotherapy: Cryptic anticancer vaccines. Semin Immunol 2010;22:113-24.

9. Nobler MP. The Abscopal Effect in Malignant Lymphoma and Its Relationship to Lymphocyte Circulation. Radiology 1969;93:410-2.

10. Stone HB, Peters LJ, Milas L. Effect of host immune capability on radiocurability and subsequent transplantability of a murine fibrosarcoma. J Natl Cancer Inst 1979;63:1229-35.

11. Formenti SC, Demaria S. Systemic effects of local radiotherapy. Lancet Oncol 2009;10:718-26.

12. Formenti SC, Demaria S. Combining Radiotherapy and Cancer Immunotherapy: A Paradigm Shift. JNCI 2013;105:256-65.

13. Frey B, Rubner $\mathrm{Y}$, Wunderlich R, et al. Induction of Abscopal Anti-Tumor Immunity and Immunogenic Tumor Cell Death by Ionizing Irradiation - Implications for Cancer Therapies. Curr Med Chem 2012;19:1751-64.

14. Sharabi AB, Lim M, Deweese TL, et al. Radiation and checkpoint blockade immunotherapy: radiosensitisation and potential mechanisms of synergy. Lancet Oncol 2015;16:e498-509.

15. Tang C, Wang X, Soh H, et al. Combining Radiation and Immunotherapy: A New Systemic Therapy for Solid Tumors? Cancer Immunol Res 2014;2:831-8.

16. Abuodeh Y, Venkat P, Kim S. Systematic review of case reports on the abscopal effect. Curr Probl Cancer 2016;40:25-37.

17. Vesely MD, Kershaw MH, Schreiber RD, et al. Natural Innate and Adaptive Immunity to Cancer. Annu Rev Immunol 2011;29:235-71.

18. Kang J, Demaria S, Formenti S. Current clinical trials testing the combination of immunotherapy with radiotherapy. J Immunother Cancer 2016;4:51.

19. Weichselbaum RR, Liang H, Deng L, et al. Radiotherapy and immunotherapy: a beneficial liaison? Nat Rev Clin Oncol 2017;14:365-79.

20. Stewart TJ, Smyth MJ. Improving cancer immunotherapy by targeting tumor-induced immune suppression. Cancer Metastasis Rev 2011;30:125-40.

21. Muro K, Chung HC, Shankaran V, et al. Pembrolizumab for patients with PD-L1-positive advanced gastric cancer (KEYNOTE-012): a multicentre, open-label, phase 1b trial. Lancet Oncol 2016;17:717-26.

22. Thompson ED, Zahurak M, Murphy A, et al. Patterns of PD-L1 expression and CD8 T cell infiltration in gastric adenocarcinomas and associated immune stroma. Gut 2017;66:794-801.

23. Derks S, Nason KS, Liao X, et al. Epithelial PD-L2 Expression Marks Barretts Esophagus and Esophageal Adenocarcinoma. Cancer Immunol Res 2015;3:1123-9.

24. Network CGAR. Comprehensive molecular characterization of gastric adenocarcinoma. Nature 2014;513:202-9.

25. Derks S, Liao X, Chiaravalli AM, et al. Abundant PD-L1 expression in Epstein-Barr Virus-infected gastric cancers. Oncotarget 2016;7:32925-32.

26. Boyiadzis MM, Kirkwood JM, Marshall JL, et al. Significance and implications of FDA approval of pembrolizumab for biomarker-defined disease. J 
Immunother Cancer 2018;6:35.

27. Fuchs CS, Doi T, Jang RW, et al. Safety and Efficacy of Pembrolizumab Monotherapy in Patients With Previously Treated Advanced Gastric and Gastroesophageal Junction Cancer. JAMA Oncol 2018;4:e180013.

28. Kang Y-K, Boku N, Satoh T, et al. Nivolumab in patients with advanced gastric or gastro-oesophageal junction cancer refractory to, or intolerant of, at least two previous chemotherapy regimens (ONO-4538-12, ATTRACTION-2): a randomised, double-blind, placebocontrolled, phase 3 trial. Lancet 2017;390:2461-71.

29. Shitara K, Özgüroğlu M, Bang YJ, et al. KEYNOTE-061: Phase 3 study of pembrolizumab vs paclitaxel for previously treated advanced gastric or gastroesophageal junction (G/GEJ) cancer. Ann Oncol 2018;29:v123.

30. Kato K, Cho BC, Takahashi M, et al. Nivolumab versus chemotherapy in patients with advanced oesophageal squamous cell carcinoma refractory or intolerant to previous chemotherapy (ATTRACTION-3): a multicentre, randomised, open-label, phase 3 trial. Lancet Oncol 2019;20:1506-17.

31. Kojima T, Muro K, Francois E, et al. Pembrolizumab versus chemotherapy as second-line therapy for advanced esophageal cancer: Phase III KEYNOTE-181 study. J Clin Oncol 2019;37:2.

32. Chan BA, Jang RW, Wong RKS, et al. Improving outcomes in resectable gastric cancer: A review of current and future strategies. Oncology (Williston Park) 2016;30:635-45.

33. Smyth EC, Verheij M, Allum W, et al. Gastric cancer: ESMO Clinical Practice Guidelines for diagnosis, treatment and follow-up. Ann Oncol 2016;27:v38-49.

34. Choi AH. Perioperative chemotherapy for resectable gastric cancer: MAGIC and beyond. World J Gastroenterol 2015;21:7343.

35. Baskar R, Dai J, Wenlong N, et al. Biological response of cancer cells to radiation treatment. Front Mol Biosci 2014;1:24.

36. Miller JI, Mcintyre B, Hatcher CR Jr. Combined Treatment Approach in Surgical Management of Carcinoma of the Esophagus: A Preliminary Report. Ann Thorac Surg 1985;40:289-93.

37. Lokich JJ, Shea M, Chaffey J. Sequential infusional 5 -fluorouracil followed by concomitant radiation for tumors of the esophagus and gastroesophageal junction. Cancer 1987;60:275-9.

38. Kelsen DP, Bains M, Hilaris B, et al. Combination chemotherapy of esophageal carcinoma using cisplatin, vindesine, and bleomycin. Cancer 1982;49:1174-7.

39. Hilgenberg AD, Carey RW, Choi NC, et al. Preoperative Chemotherapy and Surgical Resection for Squamous Cell Carcinoma of the Esophagus. In: Siewert JR, Hölscher AH. editors. Diseases of the Esophagus. Berlin, Heidelberg: Springer, 1988:326-9.

40. Nigro ND, Seydel HG, Considine B, et al. Combined preoperative radiation and chemotherapy for squamous cell carcinoma of the anal canal. Cancer 1983;51:1826-9.

41. Herskovic A, Martz K, Al-Sarraf M, et al. Combined Chemotherapy and Radiotherapy Compared with Radiotherapy Alone in Patients with Cancer of the Esophagus. N Engl J Med 1992;326:1593-8.

42. Bedenne L, Michel P, Bouché O, et al. Chemoradiation Followed by Surgery Compared With Chemoradiation Alone in Squamous Cancer of the Esophagus: FFCD 9102. J Clin Oncol 2007;25:1160-8.

43. Macdonald JS, Smalley SR, Benedetti J, et al. Chemoradiotherapy after Surgery Compared with Surgery Alone for Adenocarcinoma of the Stomach or Gastroesophageal Junction. N Engl J Med 2001;345:725-30.

44. Tepper J, Krasna MJ, Niedzwiecki D, et al. Phase III Trial of Trimodality Therapy With Cisplatin, Fluorouracil, Radiotherapy, and Surgery Compared With Surgery Alone for Esophageal Cancer: CALGB 9781. J Clin Oncol 2008;26:1086-92.

45. van Heijl M, Lanschot JV, Koppert L, et al. Neoadjuvant chemoradiation followed by surgery versus surgery alone for patients with adenocarcinoma or squamous cell carcinoma of the esophagus (CROSS). BMC Surg 2008;8:21.

46. Kroemer G, Galluzzi L, Kepp O, et al. Immunogenic Cell Death in Cancer Therapy. Annu Rev Immunol 2013;31:51-72.

47. Reits EA, Hodge JW, Herberts CA, et al. Radiation modulates the peptide repertoire, enhances MHC class I expression, and induces successful antitumor immunotherapy. J Exp Med 2006;203:1259-71.

48. Klug F, Prakash H, Huber PE, et al. Low-Dose Irradiation Programs Macrophage Differentiation to an iNOS / M1 Phenotype that Orchestrates Effective T Cell Immunotherapy. Cancer Cell 2013;24:589-602.

49. Arnold KM, Flynn NJ, Raben A, et al. The Impact of Radiation on the Tumor Microenvironment: Effect of Dose and Fractionation Schedules. Cancer Growth Metastasis 2018;11:1179064418761639.

50. Matsumura S, Wang B, Kawashima N, et al. Radiation- 
Induced CXCL16 Release by Breast Cancer Cells Attracts Effector T Cells. J Immunol 2008;181:3099-107.

51. Dovedi SJ, Cheadle EJ, Popple AL, et al. Fractionated Radiation Therapy Stimulates Antitumor Immunity Mediated by Both Resident and Infiltrating Polyclonal T-cell Populations when Combined with PD-1 Blockade. Clin Cancer Res 2017;23:5514-26.

52. Schaue D, Ratikan JA, Iwamoto KS, et al. Maximizing tumor immunity with fractionated radiation. Int $\mathrm{J}$ Radiat Oncol Biol Phys 2012;83:1306-10.

53. Dewan MZ, Galloway AE, Kawashima N, et al. Fractionated but Not Single-Dose Radiotherapy Induces an Immune-Mediated Abscopal Effect when Combined with Anti-CTLA-4 Antibody. Clin Cancer Res 2009;15:5379-88.

54. Ko EC, Benjamin KT, Formenti SC. Generating antitumor immunity by targeted radiation therapy: Role of dose and fractionation. Adv Radiat Oncol 2018;3:486-93.

55. Kelly RJ, Zaidi AH, Smith MA, et al. The Dynamic and Transient Immune Microenvironment in Locally Advanced Esophageal Adenocarcinoma Post Chemoradiation. Ann Surg 2018;268:992-9.

56. Osipov A, Li Q, Thomassian S, et al. Impact of chemoradiotherapy on PD1/PDL1 expression and clinical outcomes in gastroesophageal cancers. J Clin Oncol 2017;35:4031.

57. Oh P, Du K, Leichman L, et al. PD-1 Blockade Enhances the Efficacy of Chemoradiation in a Mouse Model of Esophageal Cancer. Int J Radiat Oncol Biol Phys 2016;96(2).

58. Kelly RJ, Smith KN, Anagnostou V, et al. Neoadjuvant nivolumab plus concurrent chemoradiation in stage II/III esophageal/gastroesophageal junction cancer. J Clin Oncol 2019;37:142.
Cite this article as: Yoon K, Chen YJ, Chao J. A narrative review of combining radiation and immunotherapy in gastroesophageal cancers. Transl Cancer Res 2021;10(5):25862595. doi: $10.21037 /$ tcr-20-2210 